\title{
Widespread non-adherence to evidence-based maternity care guidelines: a population-based cluster randomised household survey
}

\author{
J Nagpal, A Sachdeva, R Sengupta Dhar, VL Bhargava, A Bhartia \\ Sitaram Bhartia Institute of Science and Research, New Delhi, India \\ Correspondence: A Bhartia, Sitaram Bhartia Institute of Science and Research, B-16, Qutab Institutional Area, New Delhi 110016, India. \\ Email abhishek.bhartia@sitarambhartia.org
}

Accepted 27 June 2014. Published Online 22 August 2014.

\begin{abstract}
Objective To assess the quality of maternity care in an Indian metropolitan city.

Study design Three-stage cluster randomised cross-sectional survey.

Setting Sixty selected colonies of Delhi.

Population One thousand eight hundred and one subjects (of 2286 eligible) were enrolled from 118446 houses. Women who had delivered a live viable birth in the past 6 months were selected for the study.
\end{abstract}

Methods In stage 1, 20 wards (of 150) were selected using a probability-proportionate-to-size systematic method. In stage 2, one colony from each income stratum (high, middle and low) was selected from each ward by simple random sampling. In stage 3 , a house-to-house survey was conducted to recruit 30 women for administering a peer-reviewed and pilot-trialled questionnaire.

Main outcome measures Caesarean section rate, induction rate and episiotomy rate.

Results National health targets such as iron supplementation advice $(>96 \%)$, tetanus vaccination $(>81 \%)$, and $\geq 3$ antenatal visits $(>90 \%)$ were largely achieved across health care facilities but not in home deliveries. Interventions were lower in public than private hospitals: caesarean section [23.7\% (20.2-27.7) versus $53.8 \%(49.3-58.3)]$, induction [20.6\% (17.5-24.25) versus $30.8 \%$ (26.8-33.2)] and episiotomy [57.8\% (52.3-63.1) versus 79.4\% (71.0-85.9)]. Private hospitals achieved better labour support rates [1.1\% (0.5-2.2) versus $14.6 \%(8.5-24.1)]$ and pain relief $[0.9 \%$ (0.4-2.0) versus $9.9(6.5-14.8)]$. Pubic hair shaving [16.2\% (11.5$22.5)$ versus $36.4 \%$ (29.9-43.4)], enema [20.2\% (15.5-26.0) versus $57.3 \%$ (49.5-64.8)], and IV fluids during labour [44.0\% (36.2$52.2)$ versus $38.7 \%(29.3-49.1)]$ were widely prevalent in public and private hospitals.

Conclusion Present practices fall short of evidence-based guidelines, with relative overuse of interventions in private hospitals and deficiency of patient-centred practices such as labour support in public hospitals.

Keywords Caesarean rate, evidence-based medicine, India, maternity care, quality of care, survey.

Please cite this paper as: Nagpal J, Sachdeva A, Sengupta Dhar R, Bhargava VL, Bhartia A. Widespread non-adherence to evidence-based maternity care guidelines: a population-based cluster randomised household survey. BJOG 2015;122:238-248.

\section{Introduction}

Quality of maternity care may be defined as 'the degree to which maternal health services for individuals and populations increase the likelihood of timely and appropriate treatment, for the purpose of achieving desired outcomes that are both consistent with current professional knowledge and uphold basic reproductive right'. ${ }^{1}$ From the public health perspective this includes accessibility, availability and ability of healthcare resources to meet minimal care guidelines across the community. However, from a care-provider perspective this primarily denotes compliance with evidence-based guidelines, as is the case with medical conditions like diabetes. ${ }^{2}$

Internationally, several studies have documented the quality of maternity care in both the public health and care provider contexts. ${ }^{3-8}$ From the public health perspective these studies have served as independent audits of prevailing maternity healthcare systems. From the clinician perspective they have offered insight into the prevalence of non-evidence based practices, providing opportunities for self-improvement. In India, the National Family Health 
Survey (NFHS) and the District Level Household Survey (DLHS) have attempted to document the quality of maternity care at the population level. ${ }^{9,10}$ However, these surveys have restricted themselves to an audit of minimal healthcare objectives such as three antenatal visits, universal iron supplementation and tetanus immunisation. Although these surveys provide useful public health data, they do not provide information on compliance with evidence-based guidelines. ${ }^{11-17}$ There is an absence of universally agreed parameters for assessing quality of maternity care (though such measures exist for other conditions ${ }^{2}$ ) and a paucity of literature on this subject internationally and from India. ${ }^{18}$ This has precluded introspection at the health system or practitioner levels. Considering that quality of care is especially important in urban centres such as Delhi where accessibility of healthcare resources is less of a limitation, we conducted a pilot study in 2008 in South Delhi. ${ }^{19}$ Our findings indicated that a substantial section of the populace were subject to overuse of investigations and interventions, while at the same time some of the minimal public health goals were not being met. The small study from a single locality did not allow generalisability or interpretation of the clinical-demographic determinants of the care provided. Hence we conducted the current 'DELhi DELivery CARE (DELCARE)' survey with the objective of evaluating the quality of maternity care in Delhi in terms of the degree to which common practices are evidence-based.

\section{Maternity services in Delhi}

Maternity care in Delhi, a city with a population of over 16 million, ${ }^{20}$ is provided in a mix of public and private facilities that vary widely in infrastructure and staffing. This includes 32 public hospitals, 564 private hospitals and nursing homes, seven primary health centres and over 250 public maternity homes. ${ }^{21}$ Most of the deliveries in the city are conducted by obstetricians. ${ }^{20}$ The obstetricians in the private sector are typically in fee-for-service solo practices, whereas midwifery is poorly developed. ${ }^{22}$ Requirement for reporting on outcomes related to maternity care is minimal at the health facility or practitioner levels. ${ }^{23}$ Insurance coverage is limited and public facilities are often overburdened. ${ }^{23}$

\section{Subjects and methods}

Participants were identified via three-stage cluster randomised sampling. Inclusion criteria were recently delivered women (180 days) who had a live, viable birth (after 28 weeks of gestation, confirmed by the primary care provider). Exclusion criteria were the inability of a participant to complete a questionnaire (subject unable to communicate, seriously ill, physical/mental disability or major cardiac, renal, hepatic, intestinal or neurological disease which required continuing treatment or hospital admission for $>1$ week within last year) or delivery outside Delhi.

\section{Study design}

The study design is presented in Figure 1. Delhi is divided into 150 wards (administrative subunits in the city, each electing one councillor; population $50000-250000^{24}$ ). In stage 1, 20 wards were selected by a probability-proportionate-to-size systematic method, based on census data, using a random computer-generated seed value. ${ }^{25}$ In stage 2 , three colonies, one from each of three socio-economic strata, were chosen from each of the 20 wards (a colony is a small administrative unit usually $1-2 \mathrm{~km}^{2}$; this constituted a cluster in our survey) by simple random sampling. In stage 3, a house-to-house survey was initiated in the chosen colonies. The starting point for each colony was the northern, southern, western or eastern extreme of the cluster (one of four was chosen at random), and the survey team moved lane-by-lane in the opposite direction (north to south, south to north, west to east or east to west) until all households were covered or a minimum of 30 willing participants were located. Permission of the local Resident Welfare Association (RWA) was sought wherever required. Participants were given a time for questionnaire administration within 2 weeks of the initial visit. The survey was conducted between September 2009 and February 2011. The cluster randomised approach stratified by socio-economic class was chosen to minimise bias and maximise representativeness and generalisability. Health facilities were classified into Hospitals ( $>25$ beds; Public or Private), Nursing Homes (5-25 beds; private) and other small Institutions ( $<5$ beds; public or private). Non-profit or NGO hospitals were included in the classification of private. Written informed consent was obtained. A free haemoglobin $(\mathrm{Hb})$ test was done, and weight and height measurements were taken; there were no other incentives. The institutional ethics committee of the Sitaram Bhartia Institute of Science and Research approved the project.

Information was recorded on a standard peer-reviewed, pilot-trialled ${ }^{19}$ questionnaire by patient recall and document verification wherever possible. This included maternal age, infant age, ethnicity, education level, annual household income, occupation, employment status and the place and type of health care provider. Socio-economic status was classified into higher, middle and lower using the income, education and occupation of the subjects in accordance with the inflation-adjusted Kuppuswamy scale (KSEC) ${ }^{26}$ (scores 3-10 were classified as Lower Socio-economic Class, LSEC; 11-15 as Middle Socio-economic Class, MSEC; and $\geq 16$ as Higher Socio-economic Class, HSEC). Detailed information was collected on quality-of-maternity care using standardised questions (see online Supporting Information). Details based on recall (not verified from records) 


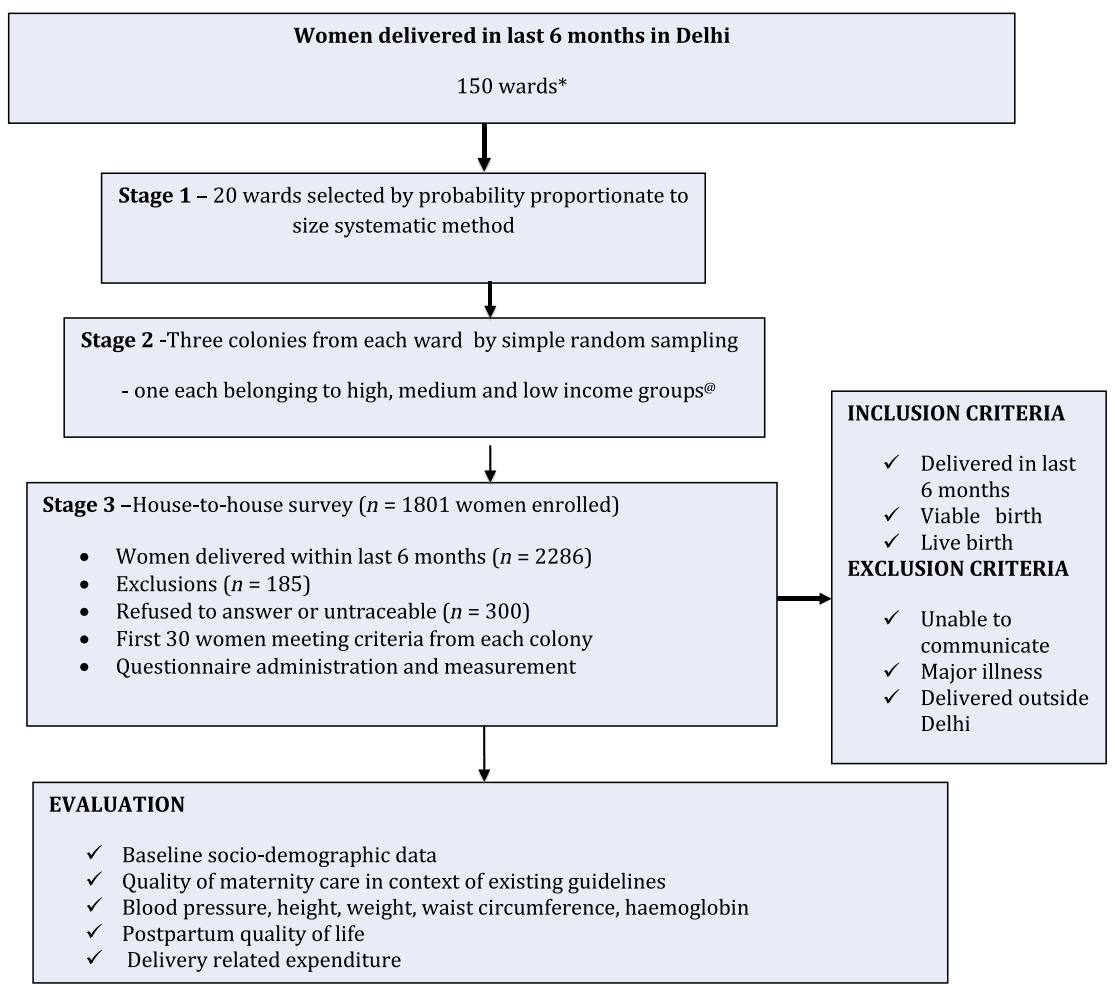

Figure 1. Summary of study design. *Delhi as an administrative unit is governed by three municipal bodies - Municipal Corporation of Delhi (MCD), New Delhi Municipal Corporation (NDMC), Delhi Cantonment Board (Armed forces included). The 150 wards comprised 134 MCD wards, seven Cantonment areas and seven NDMC areas. ${ }^{\circledR}$ Based on the MCD property tax classification ${ }^{22}$ (administrative, classification based on income used in Delhi for determining property tax; range A-G; 'A' highest; high-income areas A, B; middle income areas $C, D, E$; and low income areas F, G).

were cross-checked from the subjects' husband/mother-inlaw in the case of any discrepancies. The bilingual questionnaire (Hindi and English; see Supporting Information Appendix S1 for English version; translated and back-translated) was designed to provide information on outcomes of interest. These included minimal care objectives from the national Reproductive and Child Health $(\mathrm{RCH})$ programme such as iron supplementation, tetanus immunisation, number of antenatal visits and trained attendance during delivery using relevant questions based on the NFHS-3 questionnaire. ${ }^{10}$ We also evaluated common care provider practices in comparison with evidence-based guidelines (mobilisation in labour, early initiation of breastfeeding, labour support, antenatal counselling for preterm labour and labour analgesia, etc. ${ }^{11-17}$ ) and potentially overused or misused investigations and interventions such as induction, episiotomy, ultrasound, catheterisation, IV fluids, shaving of pubic hair. ${ }^{17}$

For Hemocue haemoglobin estimation, $20 \mu \mathrm{l}$ of blood was drawn by pinprick from the subjects to determine the prevalence of anaemia in the postpartum period. ${ }^{27}$ Weight, height and haemoglobin estimations were performed at the woman's house.

\section{Sample size considerations}

On the basis of the pilot survey ${ }^{19}$ it was estimated that a sample size of 1594 subjects would be required to calculate the prevalence of common physician practices (those with prevalence $>10 \%$ ) with an acceptable relative error of $10 \%$. This sample size calculation accounted for the estimated number of deliveries per year in Delhi and an estimated design effect of 2.0 (accounting for the cluster design ${ }^{19}$ ). We decided to recruit 30 participants from each of the 60 clusters from three strata based on the methodology adopted for the pilot survey.

\section{Analysis}

Data entry and analysis was done using PASW v 17.0 Software (SPSS Inc., Chicago, IL, USA). The results were adjusted for the three-stage stratified cluster design of the survey. Inter- and intra- cluster variation and the population of the cluster were used to 'weight' the results from the clusters, leading to an overall summary estimate of 60 such selected clusters. Complex Samples 'Descriptives' and 'Frequencies' procedures in PASW were used to provide adjusted means and frequencies where applicable. Differences between groups were evaluated on the basis 
of non-overlapping confidence intervals in estimates. Any missing data were treated as 'missing' and the data point was excluded from analysis but the subject retained.

\section{Results}

The survey team visited a total of 118446 households (60 colonies, 20 each from the higher, middle and lower income groups; 344-6759 households per colony) and identified 2286 women who had delivered within the last 6 months. There were 185 exclusions as some women had delivered outside Delhi, had a 'major medical illness' or were 'unable to communicate'. In all, 300 women (14.2\%) did not consent or were not traceable after three sequential visits to their residence. Hence, the questionnaire was administered to 1801 eligible consenting participants (588, 585 and 628 from the higher, middle and lower income areas, respectively). In all, 746 women were categorised as HSEC (41.4\%), 233 women as MSEC (12.9\%) and 813 as LSEC (45.1\%). KSEC score could not be calculated for nine mothers as available information was incomplete/not given. Complete medical records (antenatal card, delivery papers and newborn discharge) were available for 998 participants $(\sim 55 \%)$ and one or more records were available for 1457 participants.

The socio-economic and obstetric profiles of the participants are shown in Table 1 . The average age of the mothers varied between 25.0 and 28.2 years across the socio-economic spectrum. One-third of mothers were primiparous with a trend towards higher parity in lower SEC. The proportion of anaemic women was higher in the lower SEC $(47.2 \%)$ than the higher SEC (31.7\%). An obstetrician provided antenatal care to $>90 \%$ mothers from the middle and higher SEC in comparison with $66 \%$ in the LSEC. More than half of the deliveries took place in hospitals. Private hospitals and nursing homes conducted $81.2 \%$ of deliveries in the HSEC while public hospitals conducted $16.8 \%$. In the LSEC, $16.3 \%$ of all deliveries took place at private hospitals and nursing homes, whereas public hospitals conducted $50.2 \% ; 28.8 \%$ of LSEC deliveries were conducted at home.

The obstetric risk profile of the women was compared across the healthcare facilities for maternal age, primiparity, non-cephalic presentation, low birthweight (LBW; $<2500 \mathrm{~g}$ ), prematurity and twinning. There was no significant difference in the incidence of teenage pregnancies, pregnancy in $\geq 35$-year-olds, premature deliveries and non-cephalic presentations. Low birthweight babies were born to $22.8 \%$ mothers at public hospitals compared with $14.1 \%$ at private hospitals and $17.9 \%$ at nursing homes. Of mothers delivering at private facilities, $54.4 \%$ were primiparous compared with $42.2 \%$ at public hospitals.

The quality of antenatal, delivery and postnatal practices across the healthcare spectrum and national and international norms used ${ }^{11-17}$ is summarised in Tables 2 and 3.
Minimal national goals such as iron supplementation advice, tetanus vaccination and at least three antenatal visits were met in $>80 \%$ of the population, with the exception of those delivering at home. Women in private hospitals had a significantly higher number of ultrasounds (mean 4.3 versus 2.5 ), and significantly higher caesarean (53.8 versus $23.7 \%$ ) and induction (30.8 versus 20.6\%) rates compared with public hospitals. Private facilities, especially private hospitals, fared better at counselling aspects: preterm labour counselling was provided to 15.0 versus $44.2 \%$ and postnatal exercise counselling to 8.5 versus $28.3 \%$ of women in public and private hospitals, respectively. Auspicious timing was self-reported as the reason for induction by $3 \%$ of mothers delivering at private facilities. Only $\sim 1 \%$ of women received labour support and pain relief in labour in public hospitals. Episiotomy rates were universally high, and antiquated practices such as routine enemas, urinary catherisation and shaving of pubic hair were widely prevalent (7-60\% across facilities, excepting home deliveries). Family planning advice at discharge was given to only a quarter of mothers with no significant differences according to healthcare facility.

The quality of neonatal practice is summarised in Table 4. While a significantly higher proportion of the deliveries at private facilities were attended by a child specialist, non-ideal norms such as routine shifting of the baby to the nursery and delayed initiation of breastfeeding continued to be widely prevalent. Introduction of formula/animal milk feeding within 48 hours of birth and higher rates of phototherapy were also reported in private facilities. A minority of the babies stayed with the mother in the first hour after birth across the health care spectrum.

\section{Discussion}

\section{Main findings}

This cluster randomised, community-based survey reveals a poor quality of a range of maternity care practices across the healthcare spectrum in Delhi, India, and points to systemic determinants of quality of care. Although some basic public health objectives are being met, prevalent practices deviate substantially from a wide range of national and international evidence-based guidelines. This includes private institutions where the patient or insurance provider pays for care and where infrastructure resources may be less limiting. The survey highlights the overuse of investigations (ultrasounds) and interventions (caesarean section, induction, and episiotomy), especially in private facilities, and a deficiency of patient-centred practices (such as counselling and labour support) particularly in the public hospitals.

\section{Strengths and limitations}

The strengths of the study lie in sampling strategy, a large sample size, a patient-centred approach and the comparison 
Table 1. Demographic profile across the socio-economic spectrum*

\begin{tabular}{|c|c|c|c|}
\hline Characteristics & HSEC $(n=746)$ & MSEC $(n=233)$ & LSEC $(n=813)$ \\
\hline Maternal age (years) & $28.2(27.7-28.7)$ & $25.9(25.4-26.4)$ & $25.0(24.7-25.3)$ \\
\hline Body mass index $\left(\mathrm{kg} / \mathrm{m}^{2}\right)$ & $26.3(26.0-26.7)$ & $23.7(23.0-24.3)$ & $21.7(21.4-22.1)$ \\
\hline$\%$ of Anaemic women & $31.7(26.6-37.2)$ & $41.1(32.3-50.6)$ & $47.2(42.8-51.7)$ \\
\hline Baby birthweight (kg) & $2.91(2.87-2.96)$ & $2.83(2.75-2.91)$ & $2.74(2.68-2.79)$ \\
\hline Baby gender ( $\%$ male) & $53.2(48.2-58.1)$ & $44.2(37.6-51.0)$ & $53.9(51.1-56.7)$ \\
\hline \multicolumn{4}{|l|}{ Obstetric history } \\
\hline Primiparous (\%) & $45.2(41.2-49.3)$ & $36.9(31.5-42.7)$ & $27.9(25.3-30.7)$ \\
\hline Multiparous (\%) & $54.8(50.7-58.8)$ & $63.1(57.3-68.5)$ & $72.1(69.3-74.7)$ \\
\hline Previous caesarean section (\%) & $17.8(14.9-21.2)$ & $12.9(8.8-18.4)$ & $6.6(5.0-8.8)$ \\
\hline \multicolumn{4}{|l|}{ Education level completed } \\
\hline Illiterate or primary (\%) & $0.0(0.0-0.0)$ & $8.6(5.5-13.1)$ & $45.9(39.4-52.5)$ \\
\hline Middle/high school (\%) & $15.1(11.6-19.5)$ & $70.4(62.2-77.5)$ & $53.6(47.2-59.9)$ \\
\hline College education (\%) & $84.9(80.5-88.4)$ & $21.0(14.4-29.7)$ & $0.5(0.2-1.3)$ \\
\hline \multicolumn{4}{|l|}{ Gross family INCOME/month (INR)** } \\
\hline$<11750(\%)$ & $0.7(0.2-1.9)$ & $36.9(28.3-46.5)$ & $100(0.0-100)$ \\
\hline $11750-23499(\%)$ & $16.9(14.1-20.1)$ & $61.8(52.4-70.4)$ & $0.0(0.0-0.0)$ \\
\hline $23500-50000(\%)$ & $32.2(26.2-38.8)$ & $1.3(0.3-5.6)$ & $0.0(0.0-0.0)$ \\
\hline$>50000(\%)$ & $50.3(42.5-58.0)$ & $0.0(0.0-0.0)$ & $0.0(0.0-0.0)$ \\
\hline \multicolumn{4}{|l|}{ Employment status } \\
\hline Never worked (\%) & $59.5(53.3-65.4)$ & $94.4(88.1-97.5)$ & $96.7(94.6-98.0)$ \\
\hline Working full time (\%) & $6.2(3.7-10.1)$ & $0.9(0.2-3.8)$ & $1.0(0.4-2.7)$ \\
\hline Working part time (\%) & $1.5(0.6-3.5)$ & $0.4(0.1-3.4)$ & $1.1(0.4-2.8)$ \\
\hline Not working at present (\%) & $32.8(27.0-39.3)$ & $4.3(1.6-11.1)$ & $1.2(0.7-2.2)$ \\
\hline \multicolumn{4}{|l|}{ Primary caregiver } \\
\hline Obstetrician (\%) & $97.7(96.1-98.7)$ & $89.3(83.2-93.3)$ & $66.4(59.8-72.4)$ \\
\hline General lady doctor (\%) & $1.5(0.7-3.1)$ & $8.2(4.1-15.4)$ & $17.2(12.2-23.8)$ \\
\hline Some doctor (\%) & $0.5(0.2-1.4)$ & $1.3(0.3-5.3)$ & $8.2(5.0-13.2)$ \\
\hline Others (Nurse/physician assistant/TBA) (\%) & $0.0(0.0-0.0)$ & $0.9(0.2-3.6)$ & $2.0(1.0-3.9)$ \\
\hline Did not visit (\%) & $0.0(0.0-0.0)$ & $0.4(0.1-3.4)$ & $5.5(3.5-8.8)$ \\
\hline \multicolumn{4}{|l|}{ Place of delivery*** } \\
\hline Hospital (\%) & $76.0(70.6-80.7)$ & $68.7(59.2-76.8)$ & $56.9(49.1-64.5)$ \\
\hline Government (\%) & $16.8(12.3-22.4)$ & $48.9(40.6-57.4)$ & $50.2(43.8-56.6)$ \\
\hline Private $(\%)$ & $59.2(52.6-65.6)$ & $19.7(14.4-26.5)$ & $6.8(4.8-9.8)$ \\
\hline Nursing home (\%) & $22.0(17.5-27.2)$ & $18.9(13.3-26.1)$ & $9.5(6.7-13.3)$ \\
\hline Home (\%) & $0.7(0.2-1.9)$ & $6.4(3.3-10.6)$ & $28.8(21.9-36.8)$ \\
\hline Other small Institution (\%) & $1.3(0.8-2.3)$ & $6.0(3.3-10.6)$ & $4.8(2.9-7.9)$ \\
\hline
\end{tabular}

HSEC, high socio-economic class; LSEC, low socio-economic class; MSEC, middle socio-economic class; TBA, trained birth attendant.

*Data is presented as cluster-adjusted mean $(95 \% \mathrm{Cl})$ or percentage $(95 \% \mathrm{Cl})$ taking into account the survey design.

**INR (Indian rupee), Exchange rate 1 USD $=60$ INR; 1 GBP $=99$ INR (as of 13 June 2014).

***Hospital $>25$ beds; Nursing Home $5-25$ beds; Other small Institution $<5$ beds.

of community-based data with evidence-based guidelines. The collection of data by all-women staff using a validated (pilot trialled and peer reviewed) bi-lingual (Hindi and English) questionnaire also enhances the credibility of the results. The study covers a socially, culturally, educationally and ethnically diverse urban population with a multiplicity of health care models and with patchy penetrance of insurance coverage. While poor infrastructure and affordability continue to be cited as the major reasons for limited progress in maternity care across the country, ${ }^{28}$ the current study presents data from a city where many of these factors may be less significant limitations, shifting the focus to the healthcare providers and systematic flaws (Delhi has one of the highest per-capita bed capacities and per-capita income in the country ${ }^{21}$ ). The questionnaire-based survey methodology is limited by biases of recall, recency, belief and hindsight. However, lack of reliable birth registration data and the amorphous multiplicity of service providers precluded any other study design. The quality of care may have been overestimated due to the exclusion of non-live births. The 
Table 2. Quality of antenatal care across healthcare facilities*

\begin{tabular}{|c|c|c|c|c|c|c|}
\hline \multirow[t]{2}{*}{ Characteristics } & \multicolumn{2}{|c|}{ Hospital } & \multirow{2}{*}{$\begin{array}{l}\text { Nursing home } \\
\quad(n=285)\end{array}$} & \multirow{2}{*}{$\begin{array}{c}\text { Home } \\
(n=256)\end{array}$} & \multirow{2}{*}{$\begin{array}{l}\text { Other small } \\
\text { institutions } \\
\quad(n=63)\end{array}$} & \multirow[t]{2}{*}{ Evidence } \\
\hline & $\begin{array}{l}\text { Government } \\
\quad(n=649)\end{array}$ & $\begin{array}{c}\text { Private } \\
(n=548)\end{array}$ & & & & \\
\hline Iron supplement advised, yes (\%) & $98.6(97.3-99.3)$ & $99.5(98.3-99.8)$ & $98.2(95.9-99.3)$ & $82.4(76.8-86.9)$ & $96.8(88.5-99.2$ & $\mathrm{RCH}$ \\
\hline Iron supplement taken, yes (\%) & $92.3(89.7-94.3)$ & $97.6(95.8-98.7)$ & $95.4(92.1-97.4)$ & $69.5(63.4-75.0)$ & $85.7(75.0-92.3)$ & NICE \\
\hline \multicolumn{7}{|l|}{ Injection tetanus toxoid } \\
\hline 2 doses (\%) & $89.7(86.8-92.0)$ & $92.2(89.6-94.1)$ & $91.6(86.5-94.8)$ & $67.2(59.6-74.0)$ & $81.0(70.2-88.5)$ & $\mathrm{RCH}$ \\
\hline 1 dose $(\%)$ & $7.4(5.6-9.7)$ & $4.6(3.0-6.9)$ & $5.6(3.4-9.2)$ & $18.8(13.0-26.3)$ & $15.9(9.5-25.3)$ & \\
\hline Not received (\%) & $1.2(0.6-2.5)$ & $1.1(0.3-3.4)$ & $1.8(0.6-4.8)$ & $12.9(9.4-17.5)$ & $3.2(0.9-10.7)$ & \\
\hline Urine tested $>2$ visits (\%) & $52.7(47.3-58.0)$ & $75.4(67.6-81.8)$ & $52.6(44.3-60.8)$ & $19.9(14.5-26.7)$ & $41.3(32.0-51.2)$ & NICE \\
\hline $\begin{array}{l}\text { Haemoglobin tested at } \\
\text { least once }(\%)\end{array}$ & $88.9(84.3-92.3)$ & $98.9(97.4-99.5)$ & $93.3(89.6-95.8)$ & $49.6(43.6-55.7)$ & $71.4(55.4-83.4)$ & WHO \\
\hline Triple test done $(\%)^{\star \star}$ & $6.0(3.8-9.3)$ & $43.6(37.1-50.3)$ & $11.9(7.8-17.7)$ & $0.4(0.0-3.3)$ & $0.0(0.0-0.0)$ & NICE \\
\hline \multicolumn{7}{|l|}{ Ultrasound } \\
\hline Done (one or more; \%) & $95.5(93.0-97.2)$ & $99.6(97.4-100.0)$ & $98.6(95.5-99.6)$ & $68.4(60.0-75.8)$ & $91.8(80.4-96.8)$ & NICE \\
\hline Number $(n)$ & $2.5(2.3-2.7)$ & $4.3(4.1-4.5)$ & $3.4(3.1-3.6)$ & $1.6(1.4-1.7)$ & $2.1(1.7-2.4)$ & \\
\hline$>3$ scans $(\%)^{* * *}$ & $35.3(29.9-41.0)$ & $87.8(83.6-91.0)$ & $67.4(57.4-76.0)$ & $5.5(3.1-9.4)$ & $27.0(16.3-41.3)$ & \\
\hline \multicolumn{6}{|l|}{ Counselling $(\%)$} & $\mathrm{RCH}$ \\
\hline Asked about physical/mental abuse (\%) & $1.2(0.5-3.3)$ & $2.0(1.0-3.9)$ & $0.4(0.0-3.0)$ & $0.5(0.1-3.4)$ & $1.6(0.2-12.2)$ & NICE \\
\hline Asked about feeling of sadness (\%) & $1.4(2.0-8.0)$ & $2.4(1.2-4.7)$ & $1.1(0.3-3.5)$ & $0.5(0.1-3.4)$ & $1.6(0.2-12.2)$ & NICE \\
\hline Told about Preterm labour (\%) & $15.0(11.1-20.0)$ & $44.2(36.9-51.6)$ & $27.4(20.8-35.2)$ & $4.1(2.0-8.0)$ & $16.4(7.8-31.4)$ & NICE \\
\hline Labour analgesia (\%) & $4.3(2.4-7.8)$ & $26.7(18.9-36.2)$ & $12.5(7.5-19.9)$ & $1.4(0.5-3.6)$ & $1.6(0.2-12.6)$ & NICE \\
\hline Postnatal exercises (\%) & $8.5(5.5-12.9)$ & $28.3(23.6-33.5)$ & $14.0(9.5-20.2)$ & $3.1(1.5-6.2)$ & $3.2(0.7-13.5)$ & NICE \\
\hline \multicolumn{7}{|c|}{$\begin{array}{l}\text { NICE, national Institute for Clinical Excellence }{ }^{14,15} ; \mathrm{RCH} \text {, Reproductive and Child Health }{ }^{33} \text {; WHO-A, practices that are demonstrably useful and } \\
\text { should be encouraged }{ }^{17} \text {; WHO-B, practices that are clearly harmful or ineffective and should be eliminated }{ }^{17} \text {; WHO-C, practices for which } \\
\text { insufficient evidence exists to support a clear recommendation and which should be used with caution while further research clarifies the issue }{ }^{17} \text {; } \\
\text { WHO-D, practices that are frequently used Inappropriately. }{ }^{17} \\
\text { *Data is presented as cluster adjusted mean }(95 \% \mathrm{Cl}) \text { or percentage }(95 \% \mathrm{Cl}) \text { taking into account the survey design. } \\
\text { ** Screening for Down's syndrome. } \\
* * * \text { More than what would be required in routine cases. }\end{array}$} \\
\hline
\end{tabular}

cross-sectional nature of the information limits any causeeffect inferences. The survey represents an urban metropolis which limits generalisability to the largely rural countryside but may be comparable to similar settings across the developing world.

\section{Interpretation}

Non-adherence to evidence-based standards has been reported for individual elements of our survey both globally, ${ }^{6,29,30}$ and within India ${ }^{18,19,22}$ but we have found no comparable study examining a wide range of patient-centred outcomes relating to a multitude of evidence-based guidance. Studies from developed countries report a lower prevalence of outdated practices (such as pubic hair shaving, urinary catheterisation and routine enema ${ }^{6,7}$ ), lower use of investigations (only 9.2\% of women at the National Maternity Hospital in Ireland had $>2$ ultrasounds ${ }^{31}$ ), and lower rates of interventions. ${ }^{5}$ Our results are more comparable to those from Brazil, another developing country, which has high rates for interventions and low rates for patient-centred processes of care (for example, only $1 \%$ of deliveries have labour support). ${ }^{32}$

Within India, national programmes such as the Reproductive and Child Health Programme ${ }^{33}$ and National Population Policy ${ }^{34}$ have identified a minimum of three antenatal visits, iron supplementation, and tetanus-toxoid vaccination as key outcomes; our results for these are similar to those reported in the NFHS-3 and DLHS for Delhi. ${ }^{9} 10$ The caesarean rate found in our survey is much higher than the $17 \%$ rate reported by NFHS- 3 for urban India but is comparable to the rates found in Chennai. ${ }^{18}$ What our survey adds is information on other important aspects of maternity care, such as number of ultrasounds, labour support, labour analgesia and phototherapy. In line with another study from urban India, ${ }^{35}$ we found high rates of discarding colostrum and delay in breastfeeding, in contravention to guidance from the Indian Academy of Paediatrics. ${ }^{36}$ 
Nagpal et al.

Table 3. Quality of intranatal and postnatal care across the healthcare spectrum*

\begin{tabular}{llcccc}
\hline Characteristics & \multicolumn{2}{c}{ Hospital } & $\begin{array}{c}\text { Nursing } \\
\text { homes } \\
(n=285)\end{array}$ & $\begin{array}{c}\text { Home } \\
(n=256)\end{array}$ & $\begin{array}{c}\text { Other small } \\
\text { institutions } \\
(n=63)\end{array}$ \\
\cline { 2 - 3 } & $\begin{array}{c}\text { Government } \\
(n=649)\end{array}$ & $\begin{array}{c}\text { Private } \\
(n=548)\end{array}$ & $\begin{array}{c}\text { Evidence } \\
(n=5)\end{array}$ \\
\hline
\end{tabular}

Person primarily conducting the delivery $(n=1801)$

Obstetrician (\%)

$78.4(72.0-83.7)$

General doctor (\%)

$5.9(3.8-9.0)$

$98.7(97.5-99.4) \quad 94.4(89.3-97.1)$

$0.8(0.2-3.4)$

$12.2(8.0-18.0)$

$0.5(0.2-1.7)$

$3.2(1.2-8.2)$

$1.6(0.5-5.3)$

$0.2(0.0-1.3)$

$0.5(0.2-1.7)$

$2.1(0.9-4.9)$

TBAVANM/Dai (\%)**

$0.0(0.0-0.0)$

$0.0(0.0-0.0)$

$6.6(3.9-11.0)$

$52.4(30.7-73.2)$

$\mathrm{RCH}$

$4.8(1.4-14.8)$

Mode of delivery $(n=1801)$

Vaginal (\%)

$76.3(72.3-79.8) \quad 46.2(41.7-50.7) \quad 58.6(48.6-67.9) \quad 100.0(100.0-100.0)$

$41.3(22.2-63.4)$

$\begin{array}{lll}76.3(72.3-79.8) & 46.2(41.7-50.7) & 58.6(48.6-67.9) \\ 23.7(20.2-27.7) & 53.8(49.3-58.3) & 41.4(32.1-51.4)\end{array}$

$0.0(0.0-0.0)$

Caesarean section, Total (\%)

$9.2(7.0-12.2) \quad 21.2(17.5-25.4) \quad 17.5(12.3-24.4)$

$92.1(81.8-96.8)$

$7.9(3.2-18.2)$

$4.8(1.4-14.6)$

Induction of labour $(n=1801)$

Attempted (\%)

$20.6(17.5-24.2) \quad 30.8(26.8-33.2) \quad 31.9(25.1-39.6)$

$2.7(1.1-6.5)$

$17.5(9.2-30.8)$

WHO

Routine labour practices $(n=1477)$

Labour support provided (Yes; \%)

Who provided labour support? $(n=280)$

Husband (\%)

$1.1(0.5-2.2) \quad 14.6(8.5-24.1) \quad 4.7(2.0-10.4) \quad 76.6(62.8-86.4)$

$21.3(9.0-42.4)$

WHO-A

Other relative/friend (\%)

$16.7(1.9-67.6) \quad 76.9(64.0-86.2) \quad 50.0(20.5-79.5) \quad 2.6(1.1-6.0)$

$0.0(0.0-0.0)$

How was the heart rate of the baby monitored? $(n=1085$; those who had fetal monitoring)

Intermittent auscultation -

$18.2(13.1-24.7) \quad 18.3(12.0-26.8) \quad 25.3(17.4-35.3) \quad 2.3(1.1-4.9)$

Nurse (\%)

Intermittent auscultation -

$63.3(56.5-69.7) \quad 79.1(70.4-85.8) \quad 70.1(59.5-78.9) \quad 1.2(0.3-4.6)$

WHO-D

Doctor (\%)

Continuous electronic

fetal monitoring (\%)

Shifted to another facility

$11.0(7.0-17.0) \quad 51.7(42.3-61.1) \quad 20.9(12.8-32.1)$

$0.0(0.0-0.0)$

during labour (\%)

$4.9(3.1-7.7) \quad 1.8(0.8-3.9) \quad 4.2(2.2-7.9) \quad 15.2(10.4-21.7)$

$0.0(0.0-0.0)$

Routine vaginal delivery practices $(n=1229)$

Episiotomy given (\%)

Shaving pubic hair (\%)

Enema given (\%)

Urinary catheterisation (\%)

$57.8(52.3-63.1) \quad 79.4(71.0-85.9) \quad 70.1(60.5-78.1)$

$16.2(11.5-22.2) \quad 36.4(29.9-43.4) \quad 26.3(18.2-36.5)$

$0.8(0.2-3.2)$

$3.5(1.3-9.4)$

$0.4(0.1-2.9)$

$20.2(15.5-26.0) \quad 57.3(49.5-64.8) \quad 50.3(41.9-58.7)$

$0.0(0.0-0.0)$

$5.7(3.5-9.1) \quad 15.4(9.7-23.6) \quad 7.8(4.4-13.5)$

$0.0(0.0-0.0)$

Pain relief measures during labour (\%)

$0.9(0.4-2.0)$

$9.9(6.5-14.8) \quad 2.7(1.0-7.5)$

$0.0(0.0-0.0) \quad 0.8(0.2-3.1) \quad 0.0(0.0-0.0)$

$0.0(0.0-0.0) \quad 0.8(0.2-3.1) \quad 0.0(0.0-0.0)$

$0.0(0.0-0.0)$

$0.0(0.0-0.0)$

$0.6(0.2-1.8) \quad 7.9(4.0-15.1) \quad 3.0(1.1-8.1)$

$0.0(0.0-0.0)$

Epidural analgesia (\%)

Mobility during labour (\%)

$58.2(51.0-65.1) \quad 58.1(51.4-64.5) \quad 54.5(42.1-66.4)$

$83.2(73.0-90.1)$

Oral fluids during labour/delivery (\%)

Intravenous fluid during labour (\%)

$54.1(48.1-60.1) \quad 58.1(49.4-66.3) \quad 53.9(44.5-63.1)$

$70.3(61.6-77.7)$

$44.0(36.2-52.2) \quad 38.7(29.3-49.1) \quad 64.7(53.2-74.7)$

$1.2(0.4-3.3)$

Oxytocics during labour (\%)

$23.6(15.4-34.5) \quad 44.7(30.5-59.8) \quad 44.3(33.7-55.5)$

$0.8(0.2-3.1)$

$10.7(7.7-14.8) \quad 9.1(5.5-14.8) \quad 10.8(6.4-17.6)$

$1.6(0.6-3.9)$

$11.1(5.2-22.3)$

( $n=1229)$

Lithotomy (\%)

On your back (\%)

48.9 (39.8-58.0) $71.1(57.9-81.5) \quad 67.7(55.0-78.2)$

$2.0(0.8-4.7)$

$49.7(40.5-58.9) \quad 26.5(16.8-39.2) \quad 32.3(21.8-45.0)$

$77.3(69.3-83.8)$

$41.4(25.8-59.0)$

WHO-D

$12.1(4.1 .-30.8)$

WHO-B

$29.3(16.3-46.9)$

WHO-B

$5.2(1.4-17.0)$

WHO-D

$0.0(0.0-0.0)$

$0.0(0.0-0.0)$

$0.0(0.0-0.0)$

$0.0(0.0-0.0)$

$53.4(30.0-75.4)$

WHO-A

WHO-D

WHO-D

$63.8(51.4-74.6)$

WHO-A

$41.4(26.0-58.7)$

WHO-A

$22.4(10.8-40.9)$

WHO-D

Non-Supine position (\%)

Postnatal visit to mother

$0.0(0.0-0.0) \quad 1.2(0.4-3.5) \quad 0.0(0.0-0.0)$

$14.1(8.0-23.5)$

$13.8(7.1-25.1)$

$37.9(25.1-52.7)$

WHO-A

$1.1(0.6-1.6) \quad 5.8(5.0-6.7) \quad 4.0(3.0-5.0) \quad 0.1(0.03-0.2)$

$58.6(45.0-71.0)$

$0.0(0.0-0.0)$

$0.5(-0.10$ to 1.02$)$

(days from birth)

Family planning advice given (\%)

$29.1(23.4-35.6) \quad 31.6(25.6-38.2) \quad 22.5(17.5-28.4)$

$25.8(17.4-36.5)$

$31.7(18.8-48.3)$

NICE-37

NICE, National Institute for Clinical Excellence ${ }^{14,15} ; \mathrm{RCH}$, Reproductive and Child Health ${ }^{33}$; WHO-A, practices that are demonstrably useful and should be encouraged ${ }^{17}$; WHO-B, practices that are clearly harmful or ineffective and should be eliminated ${ }^{17}$; WHO-C, practices for which insufficient evidence exists to support a clear recommendation and which should be used with caution while further research clarifies the issue ${ }^{17}$; WHO-D, practices that are frequently used Inappropriately. ${ }^{17}$

*Data is presented as cluster adjusted mean $(95 \% \mathrm{Cl})$ or percentage $(95 \% \mathrm{Cl})$ taking into account the survey design. Place of delivery is defined as where the baby was finally delivered.

**TBA, trained birth attendant; ANM, auxillary nurse midwife; Dai-Untrained Traditional Birth Attendant. 
Table 4. Quality of neonatal care across the healthcare spectrum $(n=1801)$ *

\begin{tabular}{|c|c|c|c|c|c|c|}
\hline \multirow[t]{2}{*}{ Characteristics } & \multicolumn{2}{|c|}{ Hospital } & \multirow{2}{*}{$\begin{array}{l}\text { Nursing home } \\
\quad(n=285)\end{array}$} & \multirow{2}{*}{$\begin{array}{c}\text { Home } \\
(n=256)\end{array}$} & \multirow{2}{*}{$\begin{array}{l}\text { Other small } \\
\text { institutions } \\
\quad(n=63)\end{array}$} & \multirow[t]{2}{*}{ Evidence } \\
\hline & $\begin{array}{l}\text { Public } \\
(n=649)\end{array}$ & $\begin{array}{l}\text { Private } \\
(n=548)\end{array}$ & & & & \\
\hline $\begin{array}{l}\text { Delivery attended by child } \\
\text { specialist (\%) }\end{array}$ & $40.1(33.7-46.8)$ & $81.4(76.7-85.3)$ & $63.5(55.4-70.9)$ & $0.4(0.0-3.2)$ & $15.9(6.8-32.8)$ & \\
\hline \multicolumn{7}{|l|}{ Newborn care } \\
\hline $\begin{array}{l}\text { Baby shifted to nursery as routine } \\
\text { procedure (\%) }\end{array}$ & $12.6(7.6-20.3)$ & $27.4(21.2-34.5)$ & $11.2(7.9-15.8)$ & - & $4.8(1.1-18.8)$ & NICE-55 \\
\hline Baby weighed at birth (\%) & $98.8(97.3-98.8)$ & $100.0(100.0-100.0)$ & $98.9(96.7-99.7)$ & $10.2(6.7-15.1)$ & $81.0(58.1-92.9)$ & NICE-55 \\
\hline $\begin{array}{l}\text { Allowed to touch the baby } \\
\text { immediately ( }<30 \text { minutes) (\%) }\end{array}$ & $22.4(17.2-28.6)$ & $29.9(22.8-38.1)$ & $23.0(15.5-32.7)$ & $32.3(12.2-62.1)$ & $59.8(41.0-76.7)$ & NICE-55 \\
\hline $\begin{array}{l}\text { Shown baby within half an } \\
\text { hour of birth (\%) }\end{array}$ & $83.8(79.4-87.4)$ & $86.7(83.4-89.4)$ & $79.6(71.9-85.7)$ & 89.8 (78.4-95.6) & $82.5(68.8-91.0)$ & \\
\hline \multicolumn{7}{|l|}{ Newborn feeding } \\
\hline $\begin{array}{l}\text { Initiation of breastfeeding } \\
(<24 \text { hours) (\%) }\end{array}$ & $79.0(76.0-81.8)$ & $51.7(47.2-56.2)$ & $63.5(55.6-70.8)$ & $71.9(60.9-80.7)$ & $84.1(73.3-91.1)$ & NICE \\
\hline $\begin{array}{l}\text { Skilled breastfeeding support in } \\
\text { initiation of breastfeeding (\%) }\end{array}$ & $70.4(60.8-78.5)$ & $90.5(84.8-94.2)$ & $81.1(69.6-88.9)$ & - & $49.2(29.0-69.7)$ & \\
\hline Colostrum discarded (\%) & $11.7(7.1-18.7)$ & $8.2(5.7-11.6)$ & $11.9(7.7-18.1)$ & $33.6(25.0-43.5)$ & $11.1(5.7-20.6)$ & NICE \\
\hline $\begin{array}{l}\text { Formula/animal milk given within } \\
48 \text { hours (\%) }\end{array}$ & $17.7(14.7-21.1)$ & $44.5(38.8-50.4)$ & $35.4(28.3-43.3)$ & $14.5(9.2-22.1)$ & $12.7(7.0-21.9)$ & NICE \\
\hline $\begin{array}{l}\text { Formula/animal milk never } \\
\text { given }(\%)\end{array}$ & $51.9(46.9-56.9)$ & $23.4(19.1-28.2)$ & $28.1(21.6-35.6)$ & $46.0(34.2-58.4)$ & $53.9(43.8-63.7)$ & \\
\hline $\begin{array}{l}\text { Always fed formula/animal } \\
\text { milk (\%) }\end{array}$ & $3.2(1.9-5.4)$ & $8.2(4.7-13.9)$ & $6.7(4.1-10.7)$ & $3.2(0.4-20.4)$ & $5.9(2.8-11.8)$ & \\
\hline \multicolumn{7}{|l|}{ First check up of baby } \\
\hline$<1$ hour $(\%)$ & $36.2(18.8-58.2)$ & $39.1(20.3-61.7)$ & $31.2(14.9-54.1)$ & $15.2(7.6-28.3)$ & $25.4(10.2-50.5)$ & \\
\hline $1-24$ hours (\%) & $3.4(1.5-7.5)$ & $2.9(1.2-7.0)$ & $1.8(0.6-4.9)$ & $10.9(5.5-20.7)$ & - & \\
\hline $1-7$ days (\%) & $10.6(7.2-15.5)$ & $31.2(20.3-44.6)$ & $31.9(22.2-43.6)$ & $5.1(2.4-10.5)$ & $15.9(6.3-34.8)$ & \\
\hline $7-30$ days (\%) & $10.8(13.7-30.3)$ & $19.5(12.2-29.7)$ & $25.6(17.3-36.2)$ & $18.8(11.8-28.5)$ & $22.2(10.2-41.8)$ & \\
\hline >1 month/Never (\%) & $29.0(19.0-41.4)$ & $7.3(4.2-12.3)$ & $9.5(5.0-17.3)$ & $50.0(40.2-59.8)$ & $36.5(18.1-60.0)$ & \\
\hline Phototherapy given (\%) & $11.9(9.6-14.5)$ & $21.5(17.7-26.0)$ & $13.0(8.7-18.8)$ & $2.7(0.9-7.7)$ & $4.8(1.5-13.9)$ & WHO \\
\hline
\end{tabular}

The widespread departure from evidence-based guidelines is of concern for several reasons, primarily the avoidable maternal and neonatal morbidity. Medical investigations should be carried out only when indicated and their indiscriminate use is known to increase false-positives. ${ }^{37}$ This implies that the high number of ultrasounds and high electronic fetal monitoring rates may be contributing to the high caesarean rate, ${ }^{38,39}$ which will in turn fuel an increase in related short- and long- term complications. ${ }^{40,41}$ Excessive use of ultrasounds may also increase the risk for neurodevelopmental disorders. ${ }^{42,43}$ The low rates for labour support and pain relief for the majority of women across facility types are inconsistent with international guidance. ${ }^{14,17}$
It can be hypothesised that overcrowding and disempowerment of users contribute to some of the care practices seen in public hospitals. Low achievement of national health targets related to antenatal care in home deliveries probably reflects absence of care rather than a problem with the home setting per se. ${ }^{445}$ The higher intervention rates at private facilities could be hypothesised to reflect fee-for-service financial incentives, time pressures of single obstetric practice, fear of litigation, patient preference, or widespread use of ultrasounds and electronic fetal monitoring without proper indications and understanding of risk-benefit analysis. The absence of midwifery ${ }^{46}$ is probably an important limitation across facilities, as obstetrician-led practices worldwide have been shown to have higher interventions. ${ }^{47}$ 
Minimal outcome reporting requirements allow the unsatisfactory situation to remain under the radar.

\section{Conclusion}

The DELCARE survey documents prevalent practices using a population-based, community survey that provides a wider 'diagnostic' view of maternity care in Delhi. It shows that care falls substantially short of evidence-based national and international guidelines. This information should sensitise policy makers and providers towards the need for better health governance. Further work should develop a uniform set of quality measures and registries for maternity care to enable comparisons across standards, institutions, geographic areas and time. Research should be undertaken to understand the reasons for such widespread departure from guidelines and to determine how care can be better aligned with evidence.

\section{Disclosure of interest}

None reported.

\section{Contribution to authorship}

JN, RSG, VLB and $\mathrm{AB}$ contributed to the concept and design of the study. AS was involved in data collection, checking, analysis and drafting of the manuscript. $\mathrm{AB}$ and JN finalised the manuscript. $A B$ will act as guarantor for the project. All authors, external and internal, had full access to all of the data (including statistical reports and tables) in the study and can take responsibility for the integrity of the data and the accuracy of the data analysis.

\section{Details of ethics approval}

The project was approved by the institutional ethics committee of Sitaram Bhartia Institute of Science and Research (Dated 3/10/2008; SBISR/IEC/2008/03).

\section{Funding}

Supported by a grant from the Indian Council of Medical Research. The Indian Council of Medical Research approved the project protocol for funding but had no role in data collection, analysis or interpretation, in the writing of the report or in the decision to submit the article for publication. The researchers were completely independent from the funders.

\section{Acknowledgements}

Professor Suneeta Mittal (formerly at All India Institute of Medical Sciences, Delhi) and Dr Sameer Umranikar (University Hospital Southampton) commented on a draft of the paper. Professor Susan Bewley (King's College London) made extensive suggestions to improve the discussion section and the overall readability of the paper.

\section{Declaration of transparency}

The lead author affirms that this manuscript is an honest, accurate, and transparent account of the study being reported; that no important aspects of the study have been omitted; and that any discrepancies from the study as planned (and, if relevant, registered) have been explained.

\section{Supporting Information}

Additional Supporting Information may be found in the online version of this article:

Appendix S1. Questionnaire.

\section{References}

1 Hulton L, Matthews Z, Stones RW. A Framework for the Evaluation of Quality of Care in Maternity Services. Southampton, UK: University of Southampton, 2000.

2 Nagpal J, Bhartia A. Quality of diabetes care in the middle- and high-income group populace: the Delhi Diabetes Community (DEDICOM) survey. Diabetes Care 2006;29:2341-8.

3 Proctor S. What determines quality in maternity care? Comparing the perceptions of childbearing women and midwives. Birth 1998;25:85-93.

4 Hundley V, Penney G, Fitzmaurice A, van Teijlingen E, Graham W. A comparison of data obtained from service providers and service users to assess the quality of maternity care. Midwifery 2002;18:26-35.

5 Roberts CL, Tracy S, Peat B. Rates for obstetric intervention among private and public patients in Australia: population based descriptive study. BMJ 2000;15:137-41.

6 Sakala C, Corry MP. Listening to Mothers II reveals maternity care quality chasm. J Midwifery Womens Health 2007;52:183-5.

7 Lothian JA. Listening to Mothers - The First National U.S. Survey of Women's Childbearing Experiences. J Perinat Educ 2003;12:vi-viii.

8 Sanneving L, Trygg N, Saxena D, Mavalankar D, Thomsen S. Inequity in India: the case of maternal and reproductive health. Glob Health Action 2013;6:19145.

9 International Institute for Population Sciences. India National Family Health Survey (NFHS-3), 2005-06 (Vol. 1). 2007. International Institute for Population Sciences. [www.rchiips.org/nfhs/NFHS-3\%20Data/ Delhi_printed_version_for_website.pdf]. Accessed 22 April 2013.

10 The District Level Household and Facility Survey-3 2007-08. [www.rchiips.org/pdf/rch3/report/DL.pdf]. Accessed 22 April 2013.

11 Lincetto O, Mothebesoane-Anoh S, Gomez P, Munjanja SP. Antenatal care. In: Lake J, Kerber K, editors. Opportunities for Africa's Newborns: Practical Data, Policy and Programmatic Support for Newborn Care in Africa. Cape Town: PMNCH; 2006. [www.who.int/ pmnch/media/publications/africanewborns/en/webcite]. Accessed 31 March 2013.

12 Guidelines for Pregnancy Care and Management of Common Obstetric Complications by Medical Officers. Maternal Health Division Department of Family Welfare Ministry of Health \& Family Welfare Government of India 2005: 1-173.

13 National Collaborating Centre for Primary Care (UK). Postnatal Care: Routine Postnatal Care of Women and Their Babies. London: Royal College of General Practitioners (UK); 2006.

14 NICE. Intrapartum care: consultation - NICE guideline Intrapartum care: consultation - NICE guideline. 2007;1-55.

15 Antenatal care. nice.org.uk. [www.nice.org.uk/nicemedia/live/11947/ 40115/40115.pdf]. Accessed 17 April 2013. 
16 Carroli G, Mignini L. Episiotomy for vaginal birth. Cochrane Database Syst Rev 2009;(1):CD000081.

17 WHO. Care in Normal Birth: A Practical Guide. Geneva: WHO, 1996. [https://apps.who.int/rht/documents/MSM96-24/msm9624.htm]. Accessed 22 April 2013.

18 Sreevidya S, Sathiyasekaran B. High caesarean rates in Madras (India): a population-based cross sectional study. BJOG 2003; 110:106-11

19 Dhar RS, Nagpal J, Bhargava V, Sachdeva A, Bhartia A. Quality of care, maternal attitude and common physician practices across the socio-economic spectrum: a community survey. Arch Gynecol Obstet 2009;282:245-54. [http://eutils.ncbi.nlm.nih.gov/entrez/eutils/ elink.fcgi?dbfrom=pubmed\&id=19727783\&retmode=ref\&cmd=prlinks]. Accessed 19 March 2013.

20 Census of India 2011: NCT of Delhi. [www.censusindia.gov.in/2011 census/hlo/Data_sheet/delhi/Conditions_Ownership.pdf]. Accessed 15 June 2014.

21 India D, Kumar AKS, Chandra R, Banerjee R, Program B. Delhi Human Development Report 2006. New York, NY: Oxford University Press; 2006.

22 Mukherjee SN. Rising caesarean section rate. J Obstet Gynecol India 2006;56:298-300

23 Garg P, Nagpal J. A review of literature to understand the complexity of equity, ethics and management for achieving public health goals in India. J Clin Diagn Res 2014;8:1.

24 Property Tax Classification of Colonies in Delhi. Property Tax Department Municipal Corporation of Delhi. [http:// mcdpropertytax.in/colonylist.php]. Accessed 22 April 2013.

25 Raj D. The use of systematic sampling with probability proportionate to size in a large scale survey. J Am Stat Assoc 1964;59:251-5.

26 Kumar N, Shekhar C, Kumar P, Kundu AS. Kuppuswamy's socioeconomic status scale-updating for 2007. Indian J Pediatr 2007;74:1131-2.

27 Lardi AM, Hirst C, Mortimer AJ, McCollum CN. Evaluation of the HemoCue for measuring intra-operative haemoglobin concentrations: a comparison with the Coulter Max-M. Anaesthesia 1998;53:349-52.

28 Rai SK, Anand K, Misra P, Kant S, Upadhyay RP. Public health approach to address maternal mortality. Indian J Public Health 2012;56:196-203.

29 Ismail SI. An audit of NICE guidelines on antenatal pelvic floor exercises. Int Urogynecol J 2009;20:1417-22.

30 Nooh A, Baghdadi S, Raouf S. Induction of labour: how close to the evidence-based guidelines are we? J Obstet Gynecol 2005;25:451-4.

31 d'Orsi E, Chor D, Giffin K, Angulo-Tuesta A, Barbosa GP, de Gama A. National Maternity Hospital Holles Street Annual Report (nmh.ie). [www.nmh.ie/_fileupload/Annual\%20Reports/NMH2011\%20Final\% 20New.pdf]. Accessed 18 April 2013.
32 Barbosad ADSG, Reisd AC, Hartzf Z. Qualidade da atenção ao parto em maternidades do Rio de Janeiro. Rev Saúde Pública 2005;2005: 646-54.

33 Reproductive \& Child Health Programme Phase II, 2007. [http:// mohfw.nic.in/NRHM/Documents/Final_Aide_Memoire_JRM3.pdf]. Accessed 22 April 2013.

34 National Population Policy, 2000 (mohfw.nic.in). [http://mohfw.nic.in/ NRHM/Documents/national_Population_Policy_2000.pdf]. Accessed 18 April 2013.

35 Kumar D, Agarwal N, Swami HM. Socio-demographic correlates of breast-feeding in urban slums of Chandigarh. Indian J Med Sci 2006;60:461-6.

36 Infant and Young Child Feeding Chapter, Indian Academy of Pediatrics, Rajeshwari K, Bang A, Chaturvedi P, Kumar V, et al. Infant and young child feeding guidelines: 2010. Indian Pediatr 2010;47:995-1004.

37 Grimes DA, Schulz KF. Uses and abuses of screening tests. Lancet 2002;359:881-4.

38 Parry S, Severs CP, Sehdev HM, Macones GA, White LM, Morgan MA. Ultrasonographic prediction of fetal macrosomia. Association with cesarean delivery. J Reprod Med 2000;45:17-22.

39 McCusker J, Harris DR, Hosmer DW Jr. Association of electronic fetal monitoring during labor with cesarean section rate and with neonatal morbidity and mortality. Am J Public Health 1988;1988:1170-4.

40 Zelop C, Heffner LJ. The downside of cesarean delivery: short and long term complications. Clin Obstet Gynecol 2004;47:386-93.

41 Villar J, Valladares E, Wojdyla D, Zavaleta N, Carroli G, Velazco A, et al. Caesarean delivery rates and pregnancy outcomes: the 2005 WHO global survey on maternal and perinatal health in Latin America. Lancet 2006;367:1819-29.

42 Chaimay B, Woradet S. Does prenatal ultrasound exposure influence the development of children? Asia Pac J Public Health 2008;20:31-8.

43 Abramowicz Jacques S. Ultrasound and autism association, link, or coincidence? J Ultrasound Med 2012;31:1261-9.

44 de Jonge A, van der Goes BY, Ravelli AC, Amelink-Verburg MP, Mol BW, Nijhuis JG, et al. Perinatal mortality and morbidity in a nationwide cohort of 529688 low-risk planned home and hospital births. BJOG 2009;2009:1177-84.

45 Johnson KC, Daviss BA. Outcomes of planned home births with certified professional midwives: large prospective study in North America. BMJ 2005;330:1416.

46 Mavalankar D, Vora K, Prakasamma M. Achieving millennium development Goal 5: is India serious? Bull World Health Organ 2008;2008:243-243A.

47 Hatem M, Sandall J, Devane D, Soltani H, Gates S. Midwife-led versus other models of care for childbearing women. Cochrane Database Syst Rev 2008;4:CD004667. 